\title{
Editorial
}

\section{Conductas de riesgo a la adicción y violencia en adolescentes}

Características propias del desarrollo psicoevolutivo de la edad del joven, donde pasan de la niñez de pensamiento mágico a la juventud donde cree que ocurren para generar situación de felicidad donde no hay consecuencias de sus actos, la falta de control y resiliencia de consecuencia de incurrir en situación delictiva o transgresión de un tipo de delito genera problemas y escenarios posibles caóticos en la adultez. El pensamiento mágico y la falta de percepción del riesgo genera apego a adicciones, considerado por los jóvenes como etapa de la vida, es una naturalización de la adicción propio de la cultura que desde la familia se crea y percibe el adolescente.

Mitos señalan que la adolescencia es un período de conflicto con los padres. No obstante, las estadísticas señalan que la influencia de los padres es estable y fuerte si desde la niñez los vínculos familiares han sido representados por el afecto y la comprensión, existen pocas diferencias significativas, un $60 \%$ adopta los valores de los padres para resolver problemas, ese aprendizaje familiar se desarrolla en la etapa del adolescente, no hay brecha sino una relación emocional en torno a los valores. Diferencias aparecen en generaciones diversión, vestuario, gustos, diferencia superflua y no es realmente una brecha generacional.

Sin embargo, es necesario prestar atención a lo que se recibe y lo que se otorga y da a los congéneres en la etapa de adolescencia. El adolescente está construyendo su personalidad, valores, estereotipos y roles de género le moldean, se identifica con sus pares, pero en esta etapa inicia su independencia, su pensamiento científico donde afirma situaciones y considera que como los está planteando es la manera correcta. El closet de roles y oferta social respecto a expresiones de personalidad, afectivas, estereotipos relacionados con el fenómeno adictivo de los cuales debe decidir para ser el, el adulto que sueña. De esta manera, posturas de las personas frente a manejo de relaciones son asociadas a habilidades sociales con las cuales cuente un adolescente, ayudar a descubrir emociones y que tengan un adecuado uso de ellas, es labor de la comunidad para evitar conductas de riesgo, puesto que el contexto si influye en el uso y abuso de drogas legales e ilegales. Es así como los entornos donde habitan los jóvenes permea y generan tambien escenarios de unión con personas inadecuadas donde el escape y evasión propicia la violencia en la calle. 
Fenómenos de violencia en esta etapa, se vinculan a uso de drogas legales consideradas como puerta de entrada para consumo de otras (alcohol, café, tabaco, bebidas energizantes, otros) que tienden a utilizarse como mecanismo que viene a resolver una serie de problemáticas evitativas de situaciones de dificultad y frustración, así como aquellas ilegales o drogas señaladas como estupefacientes. Fuertes componentes de curiosidad, de novedad, de lo prohibido se hace atractivo a esta edad, y la depresión se agudiza al incurrir en conducta de riesgo, o en algunos casos, el estrés, ansiedad ante exigencias de sistemas educativos, de situaciones o carga de la sociedad y situación de conflicto por la necesidad de éxito inculcado por padres o competitividad puede llevar a tener fracasos donde estas situaciones frustrantes presionan a la búsqueda desinhibida del éxito y se convierten en incitadores de atender de manera rápida una situación que lleva a consumir sustancias

Otros factores que influyen se relacionan y predisponen a conductas en este espectro adictivo y ejercicio de comportamientos violentos llegan a ser los medios incitan, los juegos de video, amistades insanas, el par o amigo de la misma edad llega a ser centro de referencia en particular en la situación negativa, consecuencias no se presentan de manera inmediata, sino que se generan a mediano y largo plazo. De igual manera, existen situaciones de enamoramiento, donde la fortaleza psicológica conlleva a vincularse a pandillas para tener reconocimiento, así como situaciones en las cuales los padres o familiares llegan a mostrarse liberales, con lo cual brinda fomenta escenarios de desmedida.

Abordar esta problemática desde la perspectiva de género, señala que no hay preferencias en fenómenos de adicción o violencia, transitar modelos neoliberales reconocer fenómenos masculinos, y la tolerancia social es laxa para mujeres y hombres, donde nivel de vulnerabilidad es igual frente a estímulos, y en torno al factor lucrativo, percepciones de presencia de alcohol y diversión, como falsa percepción del buen uso del tiempo libre. Estudios muestran que se requiere alejarse de la trivialidad, inmadurez, no se deben ignorar los sentimientos, respetar y encaminar lo bueno, positivo dentro de líneas de pensamiento la adolescencia requiere control y mayor dedicación por parte de padres.

Ponerse en el lugar del otro, permite identificar factores asociados a conductas de riesgo, la vida de los jóvenes que hayan caído en la delincuencia se debe a pasado familiar conflictivo, situaciones de abuso, violencia intrafamiliar, detonantes en su desarrollo adolescente. Perdida de un ser querida tambien canaliza el duelo, de otra parte, divorcio o caminos en dinámicas familiares puede incurrir en disrupción de conductas; cambios escolares por motivos académicos sufren cambios de lugar de estudio permite que no haya un adecuado manejo de situación de estrés y es detonante en conducta de riesgo No por estar en una condición social no quiere decir que se aísla del riesgo.

Características de un joven en situación de conflicto, es tender a apartarse, elimina canales de comunicación, se encierra, no convive igual, disminuye su apetito, consume menos alimento, es irritable de manera extrema, se frustra rápidamente. Estas características deben prever el asistir a un nutricionista, psicólogo, psiquiatra que cree un canal de comunicación entre familia adolescente sin violar su autonomía y espacio. Debe ponerse cada familia en presencia de un adolescente, en un panorama futuro, cuestionarse de manera permanente, a que puede llegar si incurro en una conducta de riesgo, que puede ocurrir al llevar una vida libertina.

El fomento de solución de problemas, afrontar situaciones de cambio de vida en la familia, dejar a un lado distractores, comunicarse de manera frecuente, deben ser situaciones superables de discernimiento de manera que el joven adolescente, pueda en su conducta, manejar emociones, controlar impulsos, reacciones impulsivas, meditar y 
evaluar el efecto de las palabras que utiliza en determinado momento. Se hace importante eliminar el miedo a la verdad o negación, enfrentar situaciones y crear motivos para pensar que se es capaz de afrontar realidades positivas y negativas, generar un manejo racional emotivo, vincular a actividades familiares o de la vida del joven la relajación. Debe entonces, educarse para el manejo y desarrollo de habilidades en el manejo de emociones, en particular de emociones negativas, cultivar un pasatiempo o actividad artística, que motive y fomente el desarrollo mental y físico, los adolescentes son creativos que buscan un buen desarrollo como personas, mejorar sus condiciones de vida y desarrollarse en un entorno familiar agradable y de reconocimiento de todos sus actores.

\section{General Carlos Enrique Rodríguez González Director Dirección Nacional de Escuelas}

